\title{
Teaching about grammaticality with online tools
}

\author{
Beth Rapp Young*
}

\begin{abstract}
This paper describes an introductory online assignment for an upperdivision grammar class that helps students overcome preconceived notions about grammaticality. In anonymous end-of-semester surveys, students often label this assignment "the discussion assignment that taught me the most." This assignment helps students understand that their intuition, while useful, is not sufficient for recognizing grammatical utterances.
\end{abstract}

Keywords. grammaticality; language attitudes; grammar pedagogy; online instruction; prescriptivism

1. Introduction. When classes at my university shifted online during the pandemic in 2020 , I was already there, as I have been teaching linguistics online for 20 years. Here, I describe an introductory assignment for an upper-division grammar class that helps students overcome preconceived notions about grammaticality.

The class, Modern English Grammar, is a required elective for English majors at a large public university, and it teaches students to do fairly traditional syntactic analysis. This class is often the only linguistics class that students take, and students arrive largely unfamiliar with even basic concepts such as verb transitivity. Like many people, these students tend to conflate grammar - an understanding of how words join together to form phrases and clauses--with correctness - an avoidance of usage mistakes such as saying "10 items or less" instead of "10 items or fewer."

The conflation of grammar with correctness is unsurprising given that much of English Studies scholarship does the same. Grammar is widely perceived as a particular kind of instruction, specifically traditional drill in prescriptive grammar rules, a sort of fix-it-up attempt for the weakest writing (Kolln 1981; Brown 2009). This view led the National Council of Teachers of English to resolve in 1985 that "the teaching of grammar in isolation . . . hinders development of students' oral and written language" (quoted in Kolln \& Hancock 2005, 17-18). The avoidance of grammar persists even as those outside of English Studies view this attitude as akin to "geologists who [insist] the earth is flat" (Cole 2014, 11). Even Micciche (2004) "Making a Case for Rhetorical Grammar," which has been called "a landmark statement on productive grammar instruction" (Cole 2014), equates "formal" grammar instruction to "the deadly kind that teaches correctness divorced from content and situation" (Micciche 2004, 720). No wonder that writing teachers, in particular, shy away from any kind of grammar instruction, preferring instead to relegate grammar to "mini-lessons," taught to a subset of students, or as a small part of a class period, that avoid grammatical terminology as much as possible (Weaver 1996; Schuster 2003).

It makes sense for literature classes to focus on literature and for writing classes to focus on writing, but unfortunately, insulating students from grammar instruction makes them more vulnerable to prescriptive myths, not less. In the absence of grammar instruction, students are left with the prevailing language ideology "that coalesces around the belief that there is a 'correct' or 'pure' form of a language: Standardized English” (Metz 2018, 456) This belief is simply

\footnotetext{
* I am grateful to the organizers and participants of the "Scholarly Teaching in the Age of COVID-19 and Beyond" Symposium at the 2021 Virtual Annual Meeting of the Linguistic Society of America. Author: Beth Rapp Young, University of Central Florida (byoung@ucf.edu).
} 
regarded as "common sense" and it "includes the complementary belief that other varieties are deficient and subordinate" (Metz 2018, 456). Indeed, many students' explicit grammar knowledge seems to be primarily drawn from sources such as online memes that "resist the growing and progressive position that a wide range of Englishes exist and their usage is acceptable," and that "perpetuate beliefs about the use of correct English by making claims of superiority" (White-Farnam 2019). In this environment, English majors can come to believe that their intuitive preferences are the same as "the rules." This belief, together with ingrained cultural attitudes (Lippi-Green 2012), can lead them to be unduly judgmental towards unfamiliar language varieties - counter to goals of justice, equity, diversity, and inclusion (JEDI), and especially unhelpful for future K-12 teachers who risk unwittingly perpetuating harmful language assumptions in their own classrooms.

In my course, I seek to counter this cultural attitude by instilling a sense of marvel about how language works, curiosity about what we don't yet know, and humility about the limits of our own intuitions.

2. The "Perceived Grammaticality" assignment. Toward this end, I designed an assignment called "Perceived Grammaticality." Because this class is normally taught fully online, the assignment needed to be well-suited to an asynchronous modality. This assignment takes advantage of a "post your answer before you read other answers" setting in Canvas and the anonymity of the free "Google Forms" survey tool.

2.1. HOW THE ASSIGNMENT WORKS: The assignment has two parts, each part with a separate deadline. $^{1}$

Part 1 takes the form of a survey, hosted by Google Forms. Each question of the survey presents an example of a spoken utterance and asks students to rate the utterance as "I say," "Other group says," or "Ungrammatical." In order to introduce students to North American language varieties that might be unfamiliar to them, many examples are drawn from phenomena identified by the Yale Grammatical Diversity Project (Zanuttini, Wood, Zentz \& Horn 2018). The survey also includes a few examples of prescriptive bugaboos, such as the nauseous/nauseated distinction, and utterances that are generally viewed as standard, such as "We have some gifts for you." Finally, the survey includes two utterances that would be considered ungrammatical because they do not conform to the rules that native speakers follow. I try to find ungrammatical sentences that might pass as grammatical if you squint, i.e. not "word salad" like "book from girl library new read the the the," but something more subtle, like, "I'm a week older than Bob is old." The ungrammatical utterances are the most difficult ones to locate! I've found them in grammar textbooks and in other resources intended for English learners. I confirm the statements' ungrammaticality by checking corpora such as the Corpus of Contemporary American English (Davies 2008-) and the Corpus of Global Web-Based English (Davies 2013) to make sure that these or similar constructions do not appear.

After every student has had the opportunity to complete the survey in part 1 , the class moves to part 2. I ask students to review the aggregate ratings for every example. Google provides a pie chart view that can be shared online (with some difficulty); I generally also print this view to a

\footnotetext{
${ }^{1}$ Viewable here: https://drive.google.com/file/d/1dHTwxTYzzQzLMCl8Tah02rXMhRqrVsEd/view.

${ }^{2}$ An example of this survey is available here: https://docs.google.com/forms/d/e/1FAIpQLSd1ENVfqGSw5QJATstEOuy5r70bDVktF7GsvfhtP2M8_OjIgQ/viewform.
} 
pdf to share with the class. ${ }^{3}$ After they review the survey results, students are asked to post a message to an online discussion that answers two questions:

1. In general, what conclusions can be drawn from these results?

2. Only two of the sentences were actually ungrammatical. Which two do you think are ungrammatical and why?

I encourage students to consult an evidence-based usage dictionary, the Merriam-Webster Concise Dictionary of English Usage (2002) as they decide which utterances are ungrammatical. Using the settings in my university's Classroom Management Software (CMS), Canvas, I require students to post one message before they can view what other students have posted.

Students regularly express surprise at the varied responses to the survey. Some have never realized that "Those dishes need washed" wasn't a standard expression everywhere; others report talking themselves out of calling "The students gave the professor it" ungrammatical because they can't say what rule is violated. Sample comments:

I will say that, when said aloud, some of the other sentences struck me as statements made when we try to translate something from another language to English. I can tell you that I asked my husband to give me his opinion on these sentences because I wanted to see if we would have the same or at least similar answers since we spend so much time together. I was surprised to find that there were several sentences that we didn't agree on. It was very interesting.

"I sleep late anymore" jumped out at me when I was looking for an ungrammatical sentence, and I wanted to add the word don't before sleep (like my colleagues) to make it a negative statement. However, when I looked up anymore in my Concise Dictionary of English Usage, I was surprised to find that the word anymore has had similar positive uses in the past.

Grammar makes us squirm--at least when we are put on the spot as to whether a sentence is grammatical or not. Status is conferred on those who know what "good" grammar is, since good grammar is a reflection of how we were raised, where we grew up, and how much education we have. Our anxiety and sudden uncertainly was shown in all of the times we chose what others would say or in our perceived ungrammaticality of perfectly good sentences.

The discussion is often the most passionate of the semester. After everyone has had a chance to weigh in, I reveal the actual ungrammatical options, which some students will have successfully identified.

This assignment is designed as a formative assessment, so I grade it only on completeness and timeliness: Were both parts completed by the deadline? However, students seem to work hard to figure out which two statements are ungrammatical.

2.2. EVIDENCE THAT THE ASSIGNMENT IS EFFECTIVE. The assignment has been effective both for engaging students and for helping them learn the linguistic definition of grammaticality.

Of all the asynchronous discussions I assign, students are most likely to post "extra" messages to this one, beyond the minimum assigned number. Their tone is enthusiastic and they

\footnotetext{
${ }^{3}$ An example of survey results with student identifiers removed is viewable here:

https://drive.google.com/file/d/1xDLXZieCR2tU__EYK2OdmN5YtNqVV282/view.
} 
often relate interesting anecdotes about language in their own lives. Most students earn full credit for completing the assignment.

Over the past five years, on anonymous end-of-semester surveys, this assignment was routinely selected as "the discussion assignment that taught me the most" by a plurality of students. During the same period, a majority of students indicated that they found their usage dictionaries useful enough to keep, despite the fact that this assignment was the only assignment that required them. I interpret their desire to keep the reference book as a sign that they recognize the value of looking beyond their own intuition to answer usage questions. And on the final exams, most students define grammaticality correctly, even though most of the semester focuses on syntactic analysis, not social attitudes.

3. Conclusion. As for the larger goals of justice, equality, diversity and inclusion (JEDI), this assignment can be just a starting point. One assignment in one course is not going to overturn a longstanding cultural ideology. I try to build on this assignment with other assignments, including one that requires students to follow the unfamiliar prescriptive rules of e-prime (a constructed language variety that forbids the use of be verbs) and another that presents a text with every nth word omitted and asks students to fill in the blanks, then to reflect on which words are easier/harder to replace for which kinds of speakers. But as long as we remain immersed in a culture that views standardized "school" English as ideal, while other dialects are framed as incorrect or deficient, these efforts will likely be only partially successful.

Even when teachers explicitly set out to resist the ideology of the standard language and promote more egalitarian ideas about language, it can be difficult to do so (Milroy 2001; LippiGreen 2012). One strategy that has shown promise is for teachers to emphasize language as a social process rather than as a set of bounded language varieties, "replacing the noun language with the verb languaging" (Metz 2018, 474). The Perceived Grammaticality Survey could be expanded in that direction with examples from different time periods ranging from "Have you not?" or "Because Internet." Another option might be to supplement the assignment with critical examinations of prescriptivist grammar memes or rants (Dunn \& Lindblom 2011).

As a teacher, I enjoy talking about how English is more than just written English, and about how even native speakers have much to discover. When students have the opportunity to discover these lessons for themselves, however, these lessons seem more likely to stick.

\section{References}

Brown, David West. 2009. Coming to terms with what it means to teach and learn grammar. American Speech 84. 216-27. https://doi.org/10.1215/00031283-2009-017.

Cole, Daniel. 2014. What if the earth is flat? Working with, not against, faculty concerns about grammar in student writing. The WAC Journal 25. 7-35. https://doi.org/10.37514/WAC-J.2014.25.1.01.

Davies, Mark. 2008-. The Corpus of Contemporary American English (COCA). [Website]. https://www.english-corpora.org/coca/.

Davies, Mark. 2013. Corpus of Global Web-Based English. [Website]. https://www.english-corpora.org/glowbe/.

Dunn, Patricia \& Ken Lindblom. 2011. Grammar rants: How a backstage tour of writing complaints can help students make informed, savvy choices about their writing. Portsmouth, NH: Heinemann.

Kolln, Martha. 1981. "Closing the books on alchemy." College Composition and Communication 32(2). 139-51. https://doi.org/10.2307/356688. 
Kolln, Martha \& Craig Hancock. 2005. The story of English grammar in United States schools. English Teaching: Practice and Critique 4(3). 11-31.

Lippi-Green, Rosina. 2012. English with an accent: Language, ideology, and discrimination in the United States (2nd edition). London: Routledge.

Merriam-Webster's Concise Dictionary of English Usage. 2002. Springfield, MA: MerriamWebster.

Metz, Mike. 2018. Challenges of confronting dominant language ideologies in the high school English classroom. Research in the Teaching of English 52(4). 455-477.

Micciche, Laura R. 2004. Making a case for rhetorical grammar. College Composition and Communication 55(4). 716-37. https://doi.org/10.2307/4140668.

Milroy, James. 2001. Language ideologies and the consequences of standardization. Journal of Sociolinguistics 5(4). 530-555. https://doi.org/10.1111/1467-9481.00163.

Schuster, Edgar H. 2003. Breaking the rules: Liberating writers through innovative grammar instruction. Portsmouth, NH: Heinemann.

Weaver, Constance. 1996. Teaching grammar in context. Portsmouth, NH: Boynton/Cook.

White-Farnham, Jamie. 2019. Resisting "Let's eat Grandma": The rhetorical potential of grammar memes. Computers and Composition 52. 210-221. https://doi.org/10.1016/j.compcom.2019.02.001.

Zanuttini, Raffaella, Jim Wood, Jason Zentz \& Laurence Horn. 2018. The Yale Grammatical Diversity Project: Morphosyntactic variation in North American English. Linguistics Vanguard 4(1). 20160070. https://doi.org/10.1515/lingvan-2016-0070. 